\title{
SOME ELECTRICAL PROPERTIES OF FOREIGN AND DOMESTIC MICAS AND THE EFFECT OF ELEVATED TEMPERATURES ON MICAS
}

\author{
By A. B. Lewis, E. L. Hall, and F. R. Caldwell
}

\section{ABSTRACT}

A number of samples of mica, fairly representative of the major sources of the world's supply of mica, have been tested for dielectric constant, power factor, dielectric strength, and ability to withstand elevated temperatures. The results of these tests are as follows:

For clear ruby muscovite, in the frequency range from 100 to $1,000 \mathrm{kc}$, a dielectric constant of 7.2 and a power factor of 0.02 per cent may be expected on the average. Individual samples may be expected to vary on the average from these values by \pm 0.3 in dielectric constant and \pm 0.01 per cent in power factor. The presence of stains or inclusions so seriously affects the power factor as to render such stained micas unsuited for radio purposes. The power factor of phlogopite is found to be so high as to render it unsuited for radio purposes.

The dielectric strength of mica is found to be relatively unaffected by the presence of air bubbles, and but slightly affected by the presence of moderate amounts of stains in the form of metallic oxides. Curves showing the average dielectric strength of various classes of mica as a function of the thickness of the specimen are given.

With but two exceptions all the micas investigated were unaffected by an exposure to a temperature of $600^{\circ} \mathrm{C}$. for 30 minutes. Above that temperature the phlogopites withstood heating better than did the muscovites.

In none of these tests was it possible to make any distinction between the various micas based solely on the geographical origin of the samples.

\section{CONTENTS}

I. Introduction

II. Experimental procedure 404

1. Classification of specimens

2. Dielectric constant and power factor measurements...... 404

3. Dielectric strength measurements................ 406

4. Effects of elevated temperatures

III. Results _._.

1. Dielectric constant and power factor. 409

2. Dielectric strength......... 410

(a) Preliminary investigations... 410

(b) Final measurements...... 412

3. Effects of elevated temperatures. 416

IV. Discussion and conclusions... 417

\section{INTRODUCTION}

Much work has been done at various times and by various workers on those properties of mica which are of importance to the electrical industry. Little attempt seems to have been made, however, to make a comprehensive comparison of the properties of micas obtained from widely separated localities. Such information should be of 
interest and value to users of mica as well as to those who are called upon to set up specifications for its purchase. Such a comparison should indicate the average values of power factor or dielectric strength, for example, to be expected from the various grades of mica as well as the normal variations from those averages which must be expected in commercial lots of mica. It should indicate also whether or not there is any correlation between the properties of mica and its geographical origin. Such data would form a more satisfactory basis for the choice and specification of mica than has heretofore been available.

It was the purpose of the present investigation to compare the average dielectric constant, power factor, dielectric strength, and ability to withstand heat of micas of different qualities as well as the average differences in these properties to be expected between samples taken from the same locality, and between samples of like quality taken from widely different localities. It is recognized that this list of properties is far from complete. Many important properties, such as resistance to abrasion, ability to split into thin perfect sheets, ability to withstand rolling into small tubes, etc., have not been considered. The uses of mica are so manifold and specialized that an exhaustive investigation was not considered practicable at this time. It is believed, nevertheless, that the data presented here should be useful to both the producer and the buyer of mica.

This investigation was undertaken at the suggestion of the United States Bureau of Mines. The writers are indebted to F. W. Horton, of the Bureau of Mines, for supplying and identifying the large number of samples of mica used in these tests.

\section{EXPERIMENTAL PROCEDURE}

\section{CLASSIFICATION OF SPECIMENS}

There were available for the purposes of these tests 57 separate lots of mica. Of these, 19 lots were from foreign sources and 38 from domestic. The domestic micas consisted of ruby and green muscovite and one specimen of biotite. The foreign micas consisted of ruby muscovite from Africa, Argentine, Brazil, and India; green muscovite from Guatemala; brown mica from Africa; and amber mica or phlogopite, from Madagascar and Canada.

These micas were roughly classified when received as being clear, slightly stained, or heavily stained. For the purposes of the dielectric strength measurements the stained micas were further subdivided into two groups according to whether the staining was caused by the presence of air bubbles or of characteristic black or red inclusions. Concerning these latter stains it may be said in general that they are metallic oxides, generally iron oxides in the form of magnetite or hematite.

\section{DIELECTRIC-CONSTANT AND POWER-FACTOR MEASUREMENTS}

The power loss of a specimen is derived from the measured equivalent resistance of a circuit containing a condenser prepared from an individual sheet of the insulating material under investigation. The resistance of the circuit is again measured after replacing the sample condenser by a standard condenser whose losses are either negligible or known. The difference between the two measured values gives 
the resistance of the sample condenser. The power factor in per cent is then calculated from the equation:

Power factor (in per cent) $=6.283 \times R C f \times 10^{-7}$

where

$R=$ resistance of the sample in ohms.

$C=$ capacitance of the sample in micromicrofarads.

$f=$ frequency in kilocycles per second at which the measurement was made.

The dielectric constant is calculated from the observed data bythe following equation:

where

$$
K=\frac{11.3 C t}{S}
$$

$K=$ the dielectric constant.

$C=$ capacitance of the sample in micromicrofarads.

$t=$ thickness of the sample in centimeters.

$S=$ area of sample in square centimeters.

Further details of the method of measurement may be found in Bureau of Standards Scientific Paper No. 471, Methods of Measurement of Properties of Electrical Insulating Materials. Similar specifications for such radio-frequency measurements may be found in the American Society for Testing Materials specifications Tentative Methods of Testing Electrical Insulating Ma terials for Power Factor and Dielectric

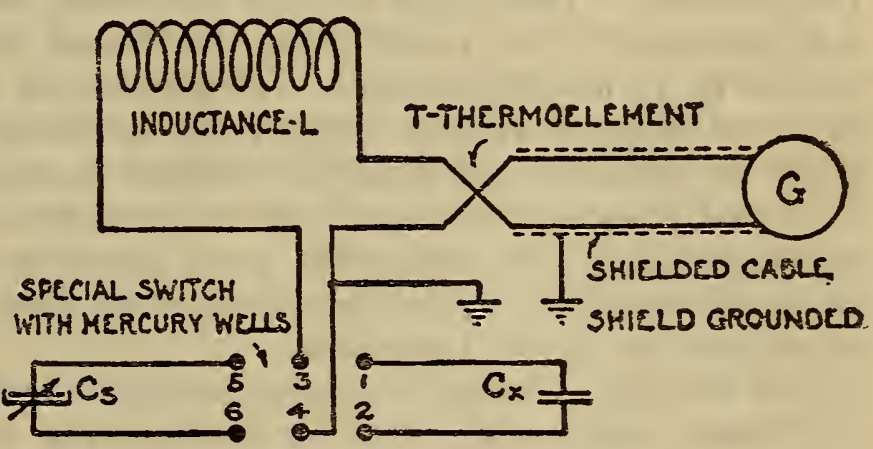

Figure 1

Constant at Frequencies of 100 to 1,500 Kilocycles, A. S. T. M. designation: D150-27T.

A schematic diagram of the circuits used is shown in figure 1.

The question of the best method of preparing the test condensers is one for which no perfectly satisfactory solution has yet been found. The usual method of floating the test specimen on mercury with an upper mercury electrode is impracticable here because of the thinness and flexibility of the samples. On the other hand, the method of inserting the sheet of material between the plates of a parallel plate condenser of known dimensions, as well as that of using mercury electrodes contained between rubber dams, ${ }^{1}$ each seems open to serious objections. Test condensers were, therefore, made up in the following manner from the samples of mica submitted. A sheet of mica was covered on one side with a sheet of tin foil, linseed oil being first applied to the mica and then removed by wiping with a clean, dry cloth. After this process, sufficient oil remained to cause the tin foil to adhere to the mica. One or two pieces of tin foil $3 \mathrm{by} 4 \mathrm{~cm}$. were then attached to the opposite side of the mica in the same manner.

1 D. W. Dye and L. Hartshorn, The Dielectric Properties of Mica, Proc. Roy. Soc., 37, pp. 42-57; 1924. $64825-31-13$ 
Care was taken to apply these small tin foil plates on sections of mica free from air pockets or other appearances of nonuniformity. It is well known that the presence of air pockets seriously affects the dielectric properties of mica. ${ }^{2}$ The use of two pieces of tin foil gave two test condensers for a given mica sample, but measurements were not made on all the condensers thus prepared. This method of preparing the sample is itself open to the objection that it introduces two films of oil of unknown thickness into the test condenser. It was found experimentally that clear muscovite specimens prepared in this manner showed a power factor of 0.01 to 0.03 per cent. (See Table 1.) This is a quantity of the order of magnitude of the sensitivity of the apparatus and of the losses present in the air condenser used as a standard. These data are taken to indicate that the effect of the oil films on the power factor is certainly not more than 0.01 per cent. The effect of the oil films on the dielectric constant is more difficult to estimate. Fortunately, however, an exact knowledge of the dielectric constant is of much less importance commercially than a knowledge of the power factor.

The capacitance of the test condenser was first measured on a direct reading microfaradmeter at 500 cycles per second. This measurement was of value in starting the measurements at radiofrequencies. Readings of the per cent relative humidity and the temperature of the room were also taken at the time of the measurements at radio-frequencies. Power-factor measurements were made on most samples at four frequencies between 100 and 1,000 kc. A few tests on some of the heavily stained samples indicated the unsuitability of these samples for use in condensers for radio purposes, and, consequently, measurements were made on only a few of the heavily stained samples. The appearance of such samples is against their selection for these purposes.

No attempt has been made to study the effect on the power factor of these samples caused by changes in temperature or humidity. Both of these factors are known to alter the power factor.

\section{DIELECTRIC STRENGTH MEASUREMENTS}

Several factors must be considered in specifying the experimental conditions under which the dielectric strength of a material is determined. It is of primary importance that the arrangement of the electrodes and the nature of the surrounding medium be such as to subject the specimen under test to a known, reproducible, and preferably uniform, electric stress. Some observers have obtained this result by using flat electrodes with well rounded edges, immersed in a medium having the same dielectric constant as the material under test. ${ }^{3}$ In this case a uniform electric stress is produced in the specimen. Other observers have used spherical electrodes, or one spherical electrode against a plane electrode. ${ }^{4}$ In case the surrounding medium has the same dielectric constant as the medium under test a nonuniform, but known, electric field is produced. In case the surrounding medium has a dielectric constant different from that of the material under test a nonuniform field is produced which

2 J. R. Werks, The Dielectric Constant of Mica, Phys. Rev., 19, pp. 319-322, 1922.

3 F. Grünwald, The Breakdown of Solid Laminated Insulating Materials Under Various Experimental Conditions, Archiv. f. Elektrot., 12, p. 79; 1923.

$1 \mathrm{~L}$. Inge and A. Walther, The Breakdown of Glass in Homogeneous and Nonhomogeneous Electric Fields, Archiv. f. Elektrot., 19, p. 257; 1927. Breakdown of Solid Insulators, Archiv. f. Elektrot., 2?, p. 410; 1929. 
is not as yet capable of computation. The American Society for Testing Materials specifications for testing sheet materials ${ }^{5}$ call for 2-inch flat electrodes immersed in oil to prevent corona and fiash over. Other observers have used mercury electrodes ${ }^{6}$ and other devices suitable for use with materials which can be worked or molded.

Within the range of ordinary power frequencies it is probable that the effect upon the breakdown voltage of a change in the frequency of the applied alternating voltage is slight. Such an effect exists, however, and it has been shown that the dielectric strength of mica at frequencies of the order of 200,000 cycles per second is appreciably lower than at 50 cycles per second. ${ }^{7}$ How much of this difference is real and how much is due to the inherent difficulties in measuring such high-frequency voltages is not certain. In the light of the theories of breakdown as caused by the formation of hot spots or hot filaments it is also important to specify the time interval during which the specimen was subjected to the electric field before breakdown occurred, as well as the temperature of the specimen.

It is assumed that such self-evident factors as the elimination of corona and flash over at the surface of the specimen and the choice of a suitable power supply need not be discussed here.

It is to be expected that the results in work of this kind will scatter widely. Where large numbers of samples are to be tested the number of observations necessary to obtain consistent results begins to be considerable. As it was the purpose of the present investigation to test a relatively large number of samples, it was necessary, in the choice of apparatus, to give considerable weight to ease and rapidity of operation. For these reasons it was decided to use as electrodes 1-inch metallic spheres immersed in a light mineral oil (transformer oil) to prevent corona and flash over. Such electrodes are easily constructed and are self-aligning in operation. Because of the fact that the spheres test only a small area of surface, a number of punctures can be made on a single sheet of material, which makes for rapidity in testing. This fact, however, will also tend to produce an increased scattering among the individual observations and to indicate a higher average dielectric strength than would be the case if flat electrodes were used. The fact that the electric field in a sheet of dielectric material placed between two spheres is not readily capable of computation is a disadvantage when comparing the results presented here with the results of other observers, but is of no great importance in the relative comparisons made in this paper.

In making the tests one of the spherical electrodes was connected to one high-voltage terminal of a step-up transformer giving a maximum of 25,000 volts and rated at 3 kilovolt amperes. The other side of the transformer as well as the other sphere was grounded. This transformer was supplied with 60-cycle alternating voltage of practically sine wave form. The high voltage was measured by means of a step-down transformer of the same ratio and rating as the supply transformer. The high-voltage coils of this step-down transformer were placed in parallel with the sphere gap and with the high-voltage coils of the step-up transformer, and the resulting secondary voltage was read from a voltmeter across the secondary terminals of the step-down transformer. These voltage readings could be made with

\footnotetext{
5 Am. Soc. Testing Materials Specification D 149-30T.

6 P. H. Moon and A. S. Norcross, Three Regions of Dielectric Breakdown, J. Am. Inst. Elec. Eng., 49 p. $125 ; 1930$.

7 See footnote 3 , p. 406
} 
an accuracy of about 1 per cent. These voltage readings multiplied by the ratio of transformation of the step-down transformer, which was accurately known, gave the total voltage across the specimen under test. The thickness measurements were made on a dial micrometer on which 0.1 mil ${ }^{8}$ could be read by estimation.

A schematic diagram of the circuit used is shown in Figure 2.

In making the tests three representative samples were taken from each lot of mica and split to thicknesses of approximately 1, 5, and 9 mils, respectively. With careful splitting it was possible to obtain specimens of sufficient size on which the thickness was constant to within 0.1 or 0.2 mil over the entire surface of the specimen. In the case of the amber micas (phlogopites), their uneven surface made this measurement uncertain to about 0.5 mil on the thicker pieces. The specimen was then inserted between the spheres and an initial low, 60 -cycle, voltage applied. The voltage was then raised continuously at the rate of approximately 800 volts per second until breakdown occurred. During this process the voltage across the secondary terminals of the step-down transformer was continuously observed

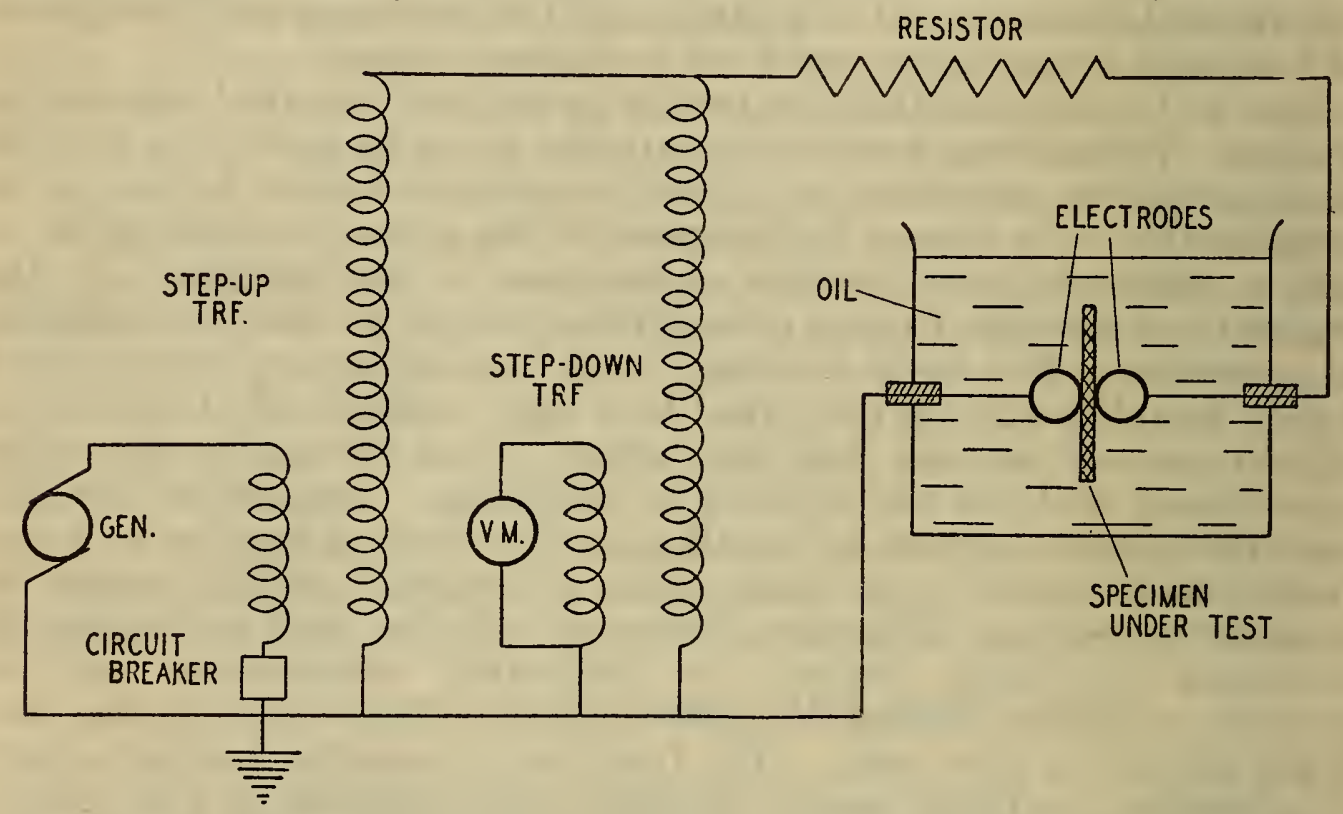

Figure 2.-Schematic diagram of dielectric-strength apparatus

by means of a voltmeter connected across its secondary terminals. The maximum reading of this voltmeter, taken at the instant breakdown occurred, when multiplied by the known ratio of transformation of the transformer, was taken to be the voltage across the specimen at the instant of breakdown. Excessive surges in the line at the instant of breakdown were prevented by a resistor of approximately $20,000 \mathrm{ohms}$ in series with the test specimen, as is shown in Figure 2.

\section{EFFECTS OF ELEVATED TEMPERATURES}

The samples used in investigating the effects of elevated temperatures were 1 by $2.5 \mathrm{~cm}$, cut from the best pieces of each kind of mica available. Eight samples of each kind were used in these tests, all samples from the same lot being originally of the same thickness. One sample from each lot was not heated. The other seven samples were heated on an alumina plate in a furnace of sensibly uniform temperature to temperatures of $600^{\circ}, 700^{\circ}, 800^{\circ}, 900^{\circ}, 1,000^{\circ}, 1,100^{\circ}$,

$81 \mathrm{mil}$ is 0.001 inch. 
and $1,200^{\circ} \mathrm{C}$., respectively, and held at these temperatures for onehalf hour. The rate of heating was rapid, the time required to reach the test temperature ranging from 35 minutes in the tests at $600^{\circ} \mathrm{C}$. to about one and one-half hours in the tests at $1,200^{\circ} \mathrm{C}$. No external force was applied to the specimens during these tests. The deformations and other changes observed are thus due solely to the temperatures to which the specimens were subjected.

After the samples had been heated they, together with the unheated samples, were mounted and examined to determine the effects of the heating. The various properties of the samples were graded according to the following scheme: $(a)$ Color, $(b)$ condition of surface, $(c)$ opacity of the sample, $(d)$ separation of laminae, $(e)$ texture, $(f)$ form and size as given by the dimensions of the sample before and after heating.

\section{RESULTS}

\section{DIELECTRIC CONSTANT AND POWER FACTOR}

A few measurements on stained micas served to confirm the wellknown conclusions of other observers that stained micas are unsuited for radio purposes. Slightly stained samples showed power factors of the order of 0.10 per cent, while heavily stained samples showed power factors of 8.0 per cent or higher. The phlogopite specimens also showed power factors of from 0.4 to 7.0 per cent. In both of these cases the power factor was a function of frequency, increasing with decreasing frequency. There was no definite evidence that the dielectric constant was a similar function of frequency, or that there was any close relation between the dielectric constant and the amount of stain present.

In the case of the clear micas, both dielectric constant and power factors were, within the accuracy of the measurements, independent of the frequency. In Table 1 are given the average values of dielectric constant and power factor obtained in the present investigation. In the same table are included, for comparison, some of the values reported in the recent literature on mica.

TABLE 1.-Dielectric-constant and power-factor measurements on mica

\begin{tabular}{|c|c|c|c|c|c|c|c|c|c|}
\hline \multirow{2}{*}{$\begin{array}{l}\text { Num- } \\
\text { ber } \\
\text { of } \\
\text { sam- } \\
\text { ples } \\
\end{array}$} & \multirow{2}{*}{ Origin } & \multirow{2}{*}{ Kind } & \multirow{2}{*}{$\begin{array}{l}\text { Ob- } \\
\text { serv- } \\
\text { ers }\end{array}$} & \multirow{2}{*}{$\begin{array}{l}\text { Tom- } \\
\text { pera- } \\
\text { ture }\end{array}$} & \multirow{2}{*}{ Frequency } & \multicolumn{2}{|c|}{$\begin{array}{c}\text { Dielectric con- } \\
\text { stant } \\
\end{array}$} & \multicolumn{2}{|c|}{ Power factor } \\
\hline & & & & & & $\begin{array}{l}\text { Aver- } \\
\text { age }\end{array}$ & Spread & $\begin{array}{l}\text { Aver- } \\
\text { age }\end{array}$ & Spread \\
\hline 16 & $\begin{array}{l}\text { United States } \\
\text { and India. }\end{array}$ & $\begin{array}{l}\text { Clear musco- } \\
\text { vite. }\end{array}$ & (1) & ${ }^{\circ} C$. & $\begin{array}{l}100-1,000 \text { kilo- } \\
\text { cycles. }\end{array}$ & 7.20 & $8.69-6.57$ & $\begin{array}{l}\text { Per } \\
\text { cent } \\
0.02\end{array}$ & $\begin{array}{l}\text { Per cent } \\
0.04-0.01\end{array}$ \\
\hline $\begin{array}{r}12 \\
4\end{array}$ & $\begin{array}{l}\text { United States. } \\
\text { India. }\end{array}$ & do & $\begin{array}{l}\text { (1) } \\
\text { (1) }\end{array}$ & $\begin{array}{l}25 \\
25\end{array}$ & oj & $\begin{array}{l}7.16 \\
7.32\end{array}$ & $\begin{array}{l}8.69-6.57 \\
7.90-7.07\end{array}$ & $\begin{array}{l}.02 \\
.02\end{array}$ & $.04-.01$ \\
\hline 4 & $\begin{array}{l}\text { United States } \\
\text { exclusive of } \\
\text { North Caro- }\end{array}$ & & (1) & 25 & - & 7.02 & 7.3 & .02 & $.03-$. \\
\hline 8 & $\begin{array}{l}\text { lina. } \\
\text { North Caro- } \\
\text { lina. }\end{array}$ & do & (1) & 25 & do. & 7.22 & $8.69-6.57$ & .02 & $.04-.01$ \\
\hline 4 & $\begin{array}{l}\text { H a y w o o d } \\
\text { County,N.C. }\end{array}$ & . do & (1) & 25 & $\mathrm{do}_{-}$ & 7. 31 & $8.69-6.57$ & .02 & $.04-.01$ \\
\hline 17 & $\begin{array}{l}\text { United States } \\
\text { and India. }\end{array}$ & $\begin{array}{l}\text { Stained mus- } \\
\text { covite. }\end{array}$ & (1) & 25 & de & & $9.64-5.83$ & & $8.36-.06$ \\
\hline 2 & Madagascar & Phlogopite & (1) & 25 & $=-d c$ & & $6.07-5.41$ & & $7.12-.3$ \\
\hline & & $\begin{array}{l}\text { Clear musco- } \\
\text { vite. }\end{array}$ & (2) & & 800 cycles & 7.0 & & & or less \\
\hline 2 & $\cdots$ & Phlogopite & (3) & $\begin{array}{l}20 \\
20 \\
\end{array}$ & _....do & 6.0 & $\ldots$ & $.68 \mid$ & $\ldots \ldots$ \\
\hline
\end{tabular}

1 Lewis, Hall, and Caldwell.

2 D. W. Dye and L. Hartshorn, The Dielectric Properties of Mica, Proc. Roy. Soc., 37, np. 42-57; 1924.

${ }^{3}$ C. Darmath and L. E. Goodall, The Permittivity and Power Factor of Micas, J. Inst. Elec. Eng. (London), 69, pp. 490-497; 1931. 


\section{DIELECTRIC STRENGTH}

\section{(a) PRELIMINARY INVESTIGATIONS}

Before describing the results of the dielectric strength measurements it will be well to mention briefly the results of some preliminary experiments. These experiments were undertaken for the purpose of determining the effects of certain variables upon the breakdown voltages obtained. Since the dielectric constant of mica is approximately 7 and that of the transformer oil approximately 2 , it is apparent that we have here the case of the nonuniform field between two spheres, and that we are unable to compute the maximum voltage gradient. We can form an approximate idea of the maximum voltage gradient, which is at the surface of the spheres, by noticing the case of two spheres immersed in a homogeneous dielectric. The

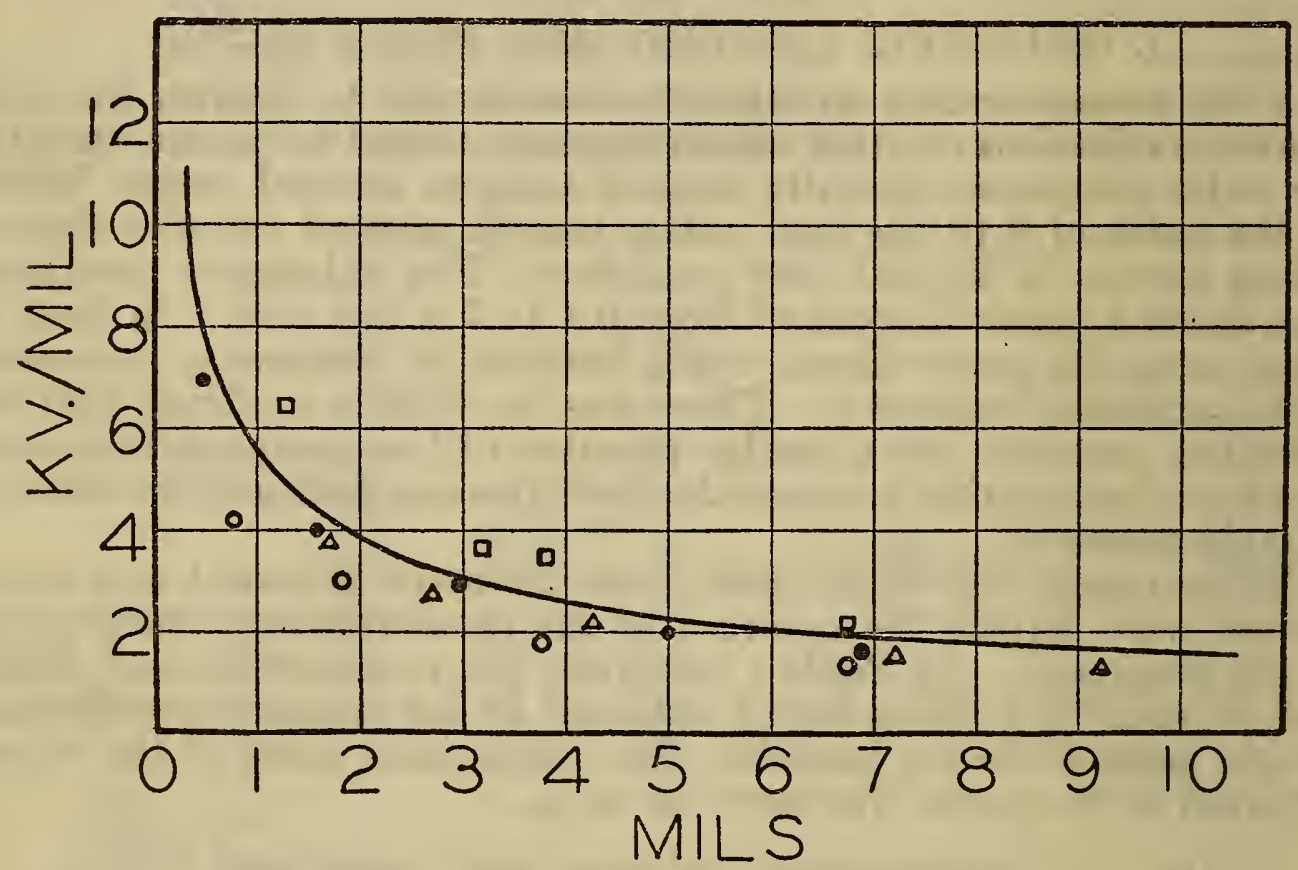

Figure 3.-Effect of electrode shape, clear muscovite

A verage of a large number of observations using 1-inch spheres. A verage deviation from the mean,

6 per cent.
Observations using 0.5 -inch spheres. Average deviation from the mean, 6 per cent.

8 Observations using 0.5 -inch sphere against a small plane. Average de iation from the mean, 4 per cent.

$\triangle$ Observations at $100^{\circ} \mathrm{C}$., using 1-inch spheres.

$\square$ Observations at $148^{\circ} \mathrm{C}$., using 1 -inch spheres.

equations for the electric field in this case are well known. ${ }^{9}$ The maximum voltage gradient is given by the expression

Where

$$
G=\frac{V}{t}\left(1+\frac{t}{3 \rho}\right)
$$

$G=$ maximum voltage gradient.

$V=$ total voltage between electrodes.

$t=$ thickness of specimen.

$\rho=$ radius of curvature of the electrodes, $\rho$ being much greater than $t$.

- A. Schuster, The Disruptive Discharge Through Gases, Phil. Mag., 29, p. 182; 1890. 
In the present case where $\rho$ is 500 mils and $t$ is 10 mils or less, the correction term $\frac{1 t}{3 \rho}$ is of the order of 1 per cent or less, vanishing with $t$.

For a like sphere against a plane the correction factor is to be multiplied by 2. Because of the normal scattering of breakdown observations we can not expect to detect with certainty differences of this order of magnitude. In Figure 3 are plotted the results obtained on a clean ruby mica from Maine, using as electrodes 1-inch spheres, 0.5 -inch spheres, and a 0.5 -inch sphere against a plane. Each point is the average of five individual punctures. The average amount, in per cent, by which each individual puncture differs from the mean of its group has been noted. The solid line represents the average of a large number of observations taken with 1-inch spheres. (See fig. 6.)

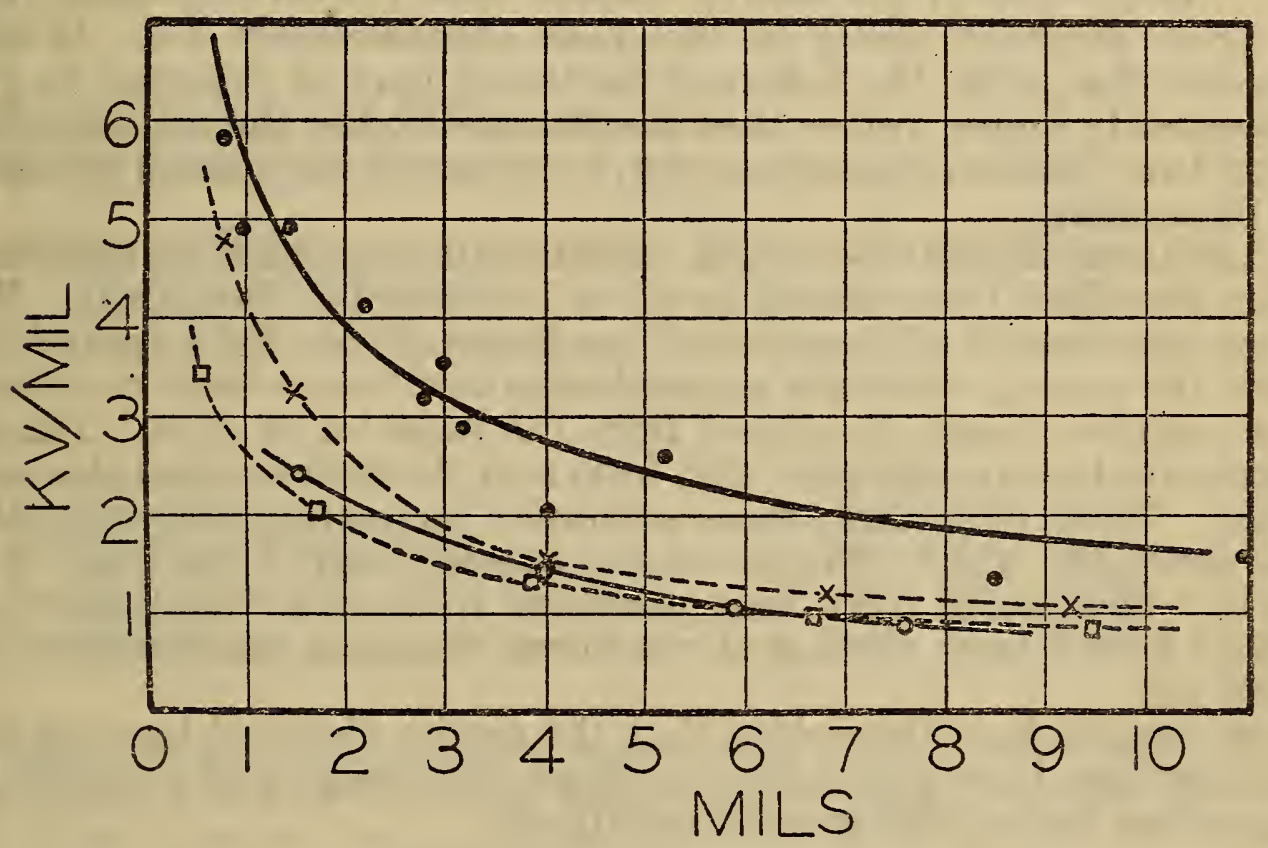

Figure 4.-Effect of electrode shape

- Clear domestic ruby, 1-inch spheres uncier oil.

Clear domestic ruby, A. S. T. M. electrodes under oil.

$x$ Heavily stained (oxides) domestic ruby, 1-inch spheres under oil

Heavily stained (oxiđes) domestic ruby, A. S. T. M. electrodes under oil. Each point represents the average of five individual observations.

It is seen that the results for the 1-inch spheres and the 0.5 -inch spheres do not differ from each other by an amount greater than that to be expected from the normal scattering of the individual observations. The results for the 0.5 -inch sphere against a plane are definitely lower than would have been predicted on the basis of the equation given above, but no further investigation of these unusually low values has been attempted. These data were taken at a temperature of about $20^{\circ} \mathrm{C}$. In the same figure are plotted the results obtained with 1 -inch spherical electrodes at two elevated temperatures, $100^{\circ}$ and $148^{\circ} \mathrm{C}$. Here again no definite effect was observed. This observation is in agreement with those of others who have reported that within this range of temperature the dielectric strength of mica is independent of temperature. ${ }^{10}$ 
In Figure 4 are shown comparisons of the results obtained on two separate samples of mica using 1-inch spherical electrodes and flat electrodes in accordance with the specifications of the American Society for Testing Materials. The solid curves represent the values obtained on a clear ruby muscovite from Maine. The dotted curves represent the values obtained on a heavily stained sample of muscovite from North Carolina. The staining material in this sample was identified as magnetite. Each of the points on these curves represents the average of five individual punctures. Within the range from 4 to 9 mils the ratio between the breakdown voltages obtained with the two kinds of electrodes is approximately constant. In the case of the clear mica from Maine this ratio $\frac{K V \text { (Spheres) }}{K V \text { (ASTM) }}$ is approximately 2.0. In the case of the heavily stained mica the corresponding ratio is again constant, being in this case approximately 1.1. It thus appears that while the spherical electrodes may be expected to give consistently higher values than the flat electrodes, the ratio between these two values is, in some manner, a function of the stained condition of the sample.

Additional dielectric-strength experiments were made on specimens after they had been soaked in oil or in water for three days. The dielectric strength of these soaked specimens did not differ appreciably from the average dielectric strength obtained from a large number of dry samples chosen at random from the same lot of mica. Finally, successive laminations were split from a single thick block of this same mica. When punctured, these successive laminations showed dielectric strengths which differed on the average only 6 per cent from those which would have been predicted from an average curve obtained from a large number of specimens chosen at random from this same lot.

It appears from these data that the results obtained here are reasonably free from errors due to small accidental and unavoidable variations in the experimental conditions.

\section{(b) FINAL MEASUREMENTS}

As stated previously, three specimens were selected at random from each lot of mica and split to thicknesses of approximately 1, 5, and 9 mils, respectively. Five observations of breakdown voltage were made on each thickness, and the average of these five observations was taken to be the breakdown voltage at that thickness. The average deviation of each individual observation from the mean of its group was computed and expressed as a percentage. The average of the three nnmbers thus obtained for each lot of mica was then taken. This "average deviation" gives a rough idea of the reproducibility of the data and the uniformity of the material. The three values of breakdown voltage obtained for each lot of mica were plotted against thiskness and a smooth curve drawn through the three points. From this curve was read the breakdown voltage (effective volts) at exactly 1,5 , and 9 mils.

These data have been summarized in Table 2 according to the origin of the mica samples and the classification of the samples. In column A have been given the average amounts, in percentage, by which the individual observations differ from the averages of the corresponding groups of observations. These numbers, therefore, represent the scat- 
tering which must be expected between observations made on a single lot of mica. In column B have been listed the average amounts by which the average breakdown voltages for an individual lot of mica differ from the corresponding average breakdown voltages for that class of mica listed in Table 2 . These numbers therefore represent the average scattering which must be expected between observations made on different lots of mica.

TABLE 2.-Average values of breakdown voltage in kilovolts (effective)

DOMESTIC MICA

\begin{tabular}{|c|c|c|c|c|c|c|}
\hline \multirow{2}{*}{$\begin{array}{c}\text { Num- } \\
\text { ber } \\
\text { of } \\
\text { lots }\end{array}$} & \multirow{2}{*}{ Classification } & \multicolumn{3}{|c|}{ Kilovolts (effective) } & \multirow{2}{*}{$\begin{array}{l}a \text {, Aver } \\
\text { age de- } \\
\text { viation } \\
\text { within } \\
\text { lots }\end{array}$} & \multirow{2}{*}{$\begin{array}{c}b \text {, A ver- } \\
\text { age de- } \\
\text { viation } \\
\text { between } \\
\text { lots }\end{array}$} \\
\hline & & 1 mil & $5 \mathrm{mils}$ & 9 mils & & \\
\hline 19 & Clear ruby (all of United Stat & 5.7 & 9.9 & 13.2 & Per cent & Per cent \\
\hline 6 & Clear ruby (United States excluding North Carolina) & 5. & 9. & 12.6 & 5 & 11 \\
\hline 13 & Clear ruby (North Carolina) & 5.7 & 10.0 & 13.3 & 6 & 10 \\
\hline 7 & Clear ruby (Yancey Co., N. C.) & 5.6 & 9.5 & 12.7 & 6 & 8 \\
\hline 9 & Ruby, air bubbles & 5.4 & 10.4 & 14.2 & 6 & 16 \\
\hline 4 & Ruby, slight metallic oxide stain & 5. 3 & 9.6 & 12.6 & 6 & 9 \\
\hline 2 & Ruby, heavy metallic oxide stain.-. & 4.1 & 9.7 & 12.0 & 7 & 13 \\
\hline 5 & 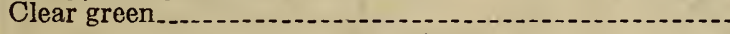 & 5.5 & 9.7 & 12.4 & 6 & \\
\hline
\end{tabular}

FOREIGN MICA

\begin{tabular}{|c|c|c|c|c|c|c|}
\hline 3 & Clear ruby (all from India). & 4.2 & 9.1 & 11.8 & 6 & \\
\hline 4 & Ruby, air bubbles & 5.4 & 10.5 & 13.5 & 5 & 10 \\
\hline 1 & Ruby, slight metallic oxide stain.- & 5.3 & 8.6 & 13. 1 & 7 & \\
\hline 5 & Ruby, heavy metallic oxide stain & 5.4 & 9.2 & 11.3 & 8 & 18 \\
\hline 1 & Clear brown (2 complete runs) ... & 5.0 & 10.9 & 15.6 & 5 & -- \\
\hline 1 & Clear green ( 2 complete runs) - - & 5.0 & 12.8 & 16.3 & 10 & \\
\hline 4 & Phlogopite & 5.0 & 11.0 & 13.2 & 6 & 10 \\
\hline
\end{tabular}

Some of the average values taken from Table 2 have been plotted in Figure 5, where the total breakdown voltage, kilovolts effective, is plotted against the thickness of the specimen in mils. It should be remarked that since the curves of Figure 5 were obtained as the averages of a number of individual curves, it is not to be expected that any one of the average curves of Figure 5 will necessarily be similar to any one of the individual curves from which it was derived.

In Figures 6 and 7 , respectively, have been plotted the results, expressed as kilovolts per mil, obtained from a large number of observations on a clear, ruby mica from Maine and a clear, green mica from Guatemala. It appears that these results can be expressed with a reasonable degree of accuracy by the empirical formula ;

$$
K V / \mathrm{mil}=\frac{A}{\sqrt{t}}+B
$$

where

$A$ and $\begin{aligned} t & =\text { thickness } \\ B & =\text { constants. }\end{aligned}$

The constants of the equations shown in Figures 6 and 7 were determined from the experimental data by the method of least squares. 


\begin{tabular}{|c|c|c|}
\hline Curve & Classification & $\begin{array}{l}\text { Number } \\
\text { of lots }\end{array}$ \\
\hline 1 & Domestic, clear ruby.- & 18 \\
\hline 2 & Domestic, stained ruby (air bubbles) & 10 \\
\hline 3 & Domestic, slightly stained ruby (metallic oxides) & \\
\hline 4 & Domestic, badly stained ruby (metallic oxides) . . & \\
\hline 5 & India, clear ruby & \\
\hline $\begin{array}{l}6 \\
7\end{array}$ & India, stained ruby (air bubbles) & \\
\hline & 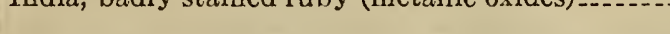 & \\
\hline
\end{tabular}

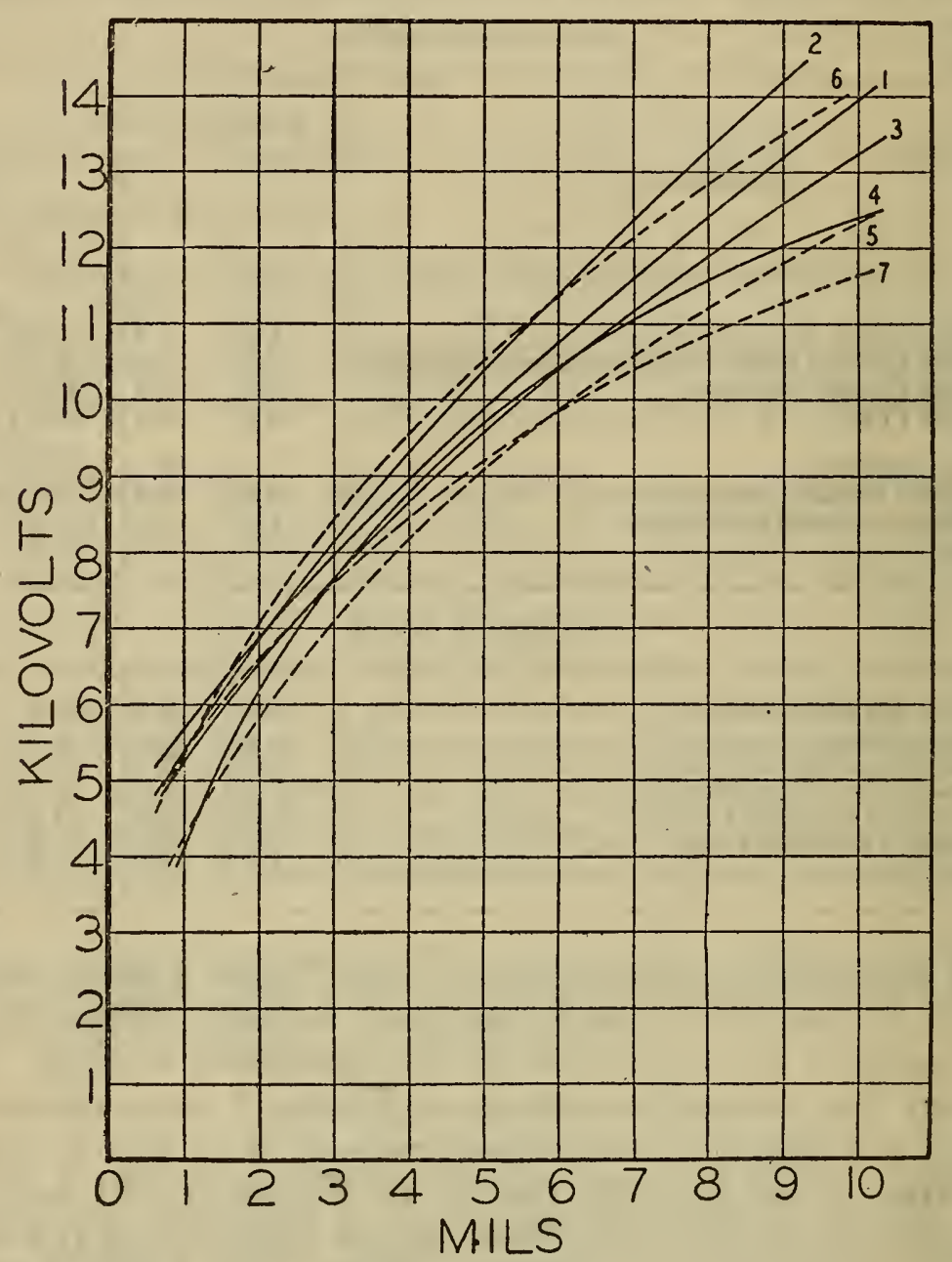

Figure 5.-Total breakdown voltage average values

In many of these tests it was observed that the actual puncture rarely took place at exactly the point of contact between the spheres and the specimen, but slightly to one side. This effect has been reported by other observers. ${ }^{11}$ In the case of the micas which were badly stained with metallic oxides and the phlogopites, "preliminary" sparks were often noticed playing about the electrodes at voltages considerably lower than that at which the actual breakdown took place. After failure of the specimen the actual puncture was observed to be surrounded by a series of charred pits.

11 E. H. Rayner, High Voltage Tests and Energy Losses in Insulating Materials, J. Inst. Elec. Eng. (London), 49, pp. 3-71, 1912. 


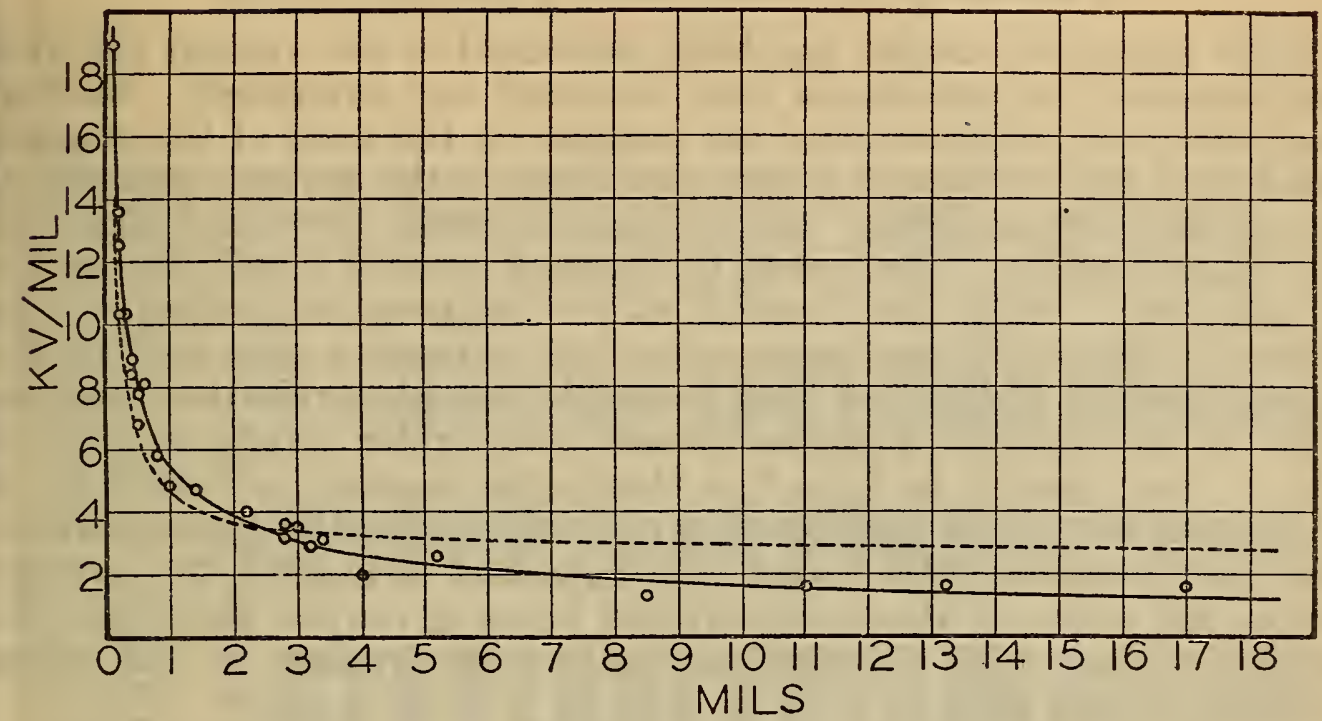

FIGURE 6.-Breakdown voltage in kilovolts per mil. Clear ruby muscovite from Maine

Observed points, each point the average of 5 individual observations.

- Plotted from the equation $\frac{K V}{\mathrm{mi} i}=\frac{5.75}{\sqrt{t}}-0.16$.

- - Plotted from the equation $\frac{k T}{\mathrm{mil}}=\frac{1.84}{t}+2.82$.

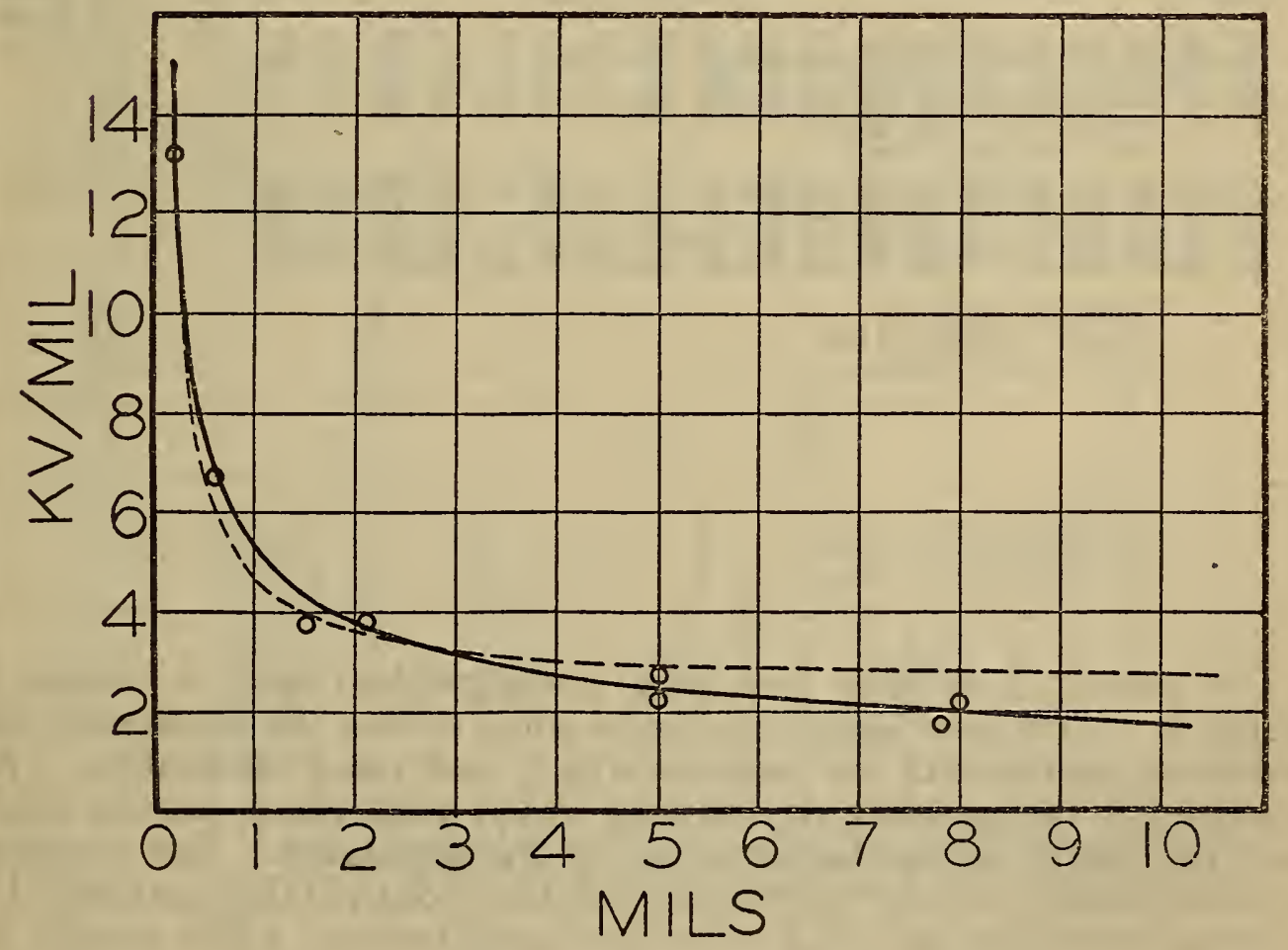

FIGURE 7.-Brealdown voltage in kilovolts per mil. Clear green muscovite from Guatemala

0 Observed points each point being the average of 5 individual observations.

- Plotted from the formula $\frac{K V}{\mathrm{mil}}=\frac{5.88}{\sqrt{t}}-0.35$.

- - Plotted from the formula $\frac{K V}{\mathrm{mil}}=\frac{2.16}{t}+2.52$. 


\section{EFFECTS OF ELEVATED TEMPERATURES}

After the mica samples had been subjected to the various elevated temperatures, the specimens were mounted and examined. Each of four observers graded each of the samples on the basis of the changes which had taken place in color, condition of the surface, opacity of the sample, separation of the laminæ, texture, form and size. In this point grading a low score indicates a general excellence in the sample after having been heated to the temperature indicated. In listing the micas at one temperature, no attention was paid to the stages through which they had passed in reaching this temperature. That is to say, if a sample showed undesirable characteristics at $700^{\circ} \mathrm{C}$. and seemed to have lost them after heating to $1,100^{\circ} \mathrm{C}$., it was graded at $1,100^{\circ} \mathrm{C}$. solely on its characteristics at this temperature. The four resulting tables were combined and averaged, the average values for some of the temperatures being given in Table 3 . No significance is to be attached to the absolute values of the scores recorded in this table.

TABLE 3.-Classes of mica in the order of their ability to withstand elevated temperalures

[A small score indicates relative excellence in the samples after having been heated to the temperature indicated]

$700^{\circ} \mathrm{C}$.

\begin{tabular}{c|c|c}
\hline \multirow{2}{*}{ Rating } & Class and origin & $\begin{array}{c}\text { A verage } \\
\text { points } \\
\text { scored }\end{array}$ \\
\hline 1 & Phlogopite, 7 lots & 30 \\
\hline
\end{tabular}

$900^{\circ} \mathrm{C}$.

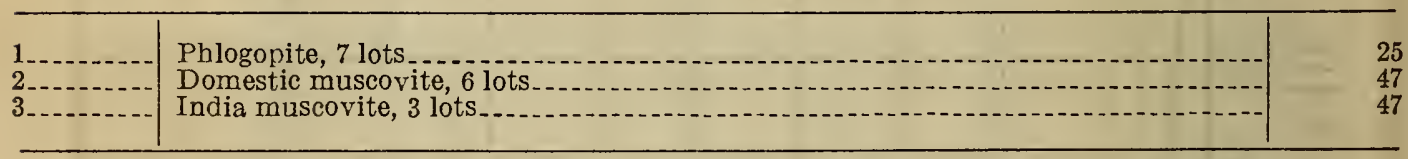

$1,100^{\circ} \mathrm{C}$.

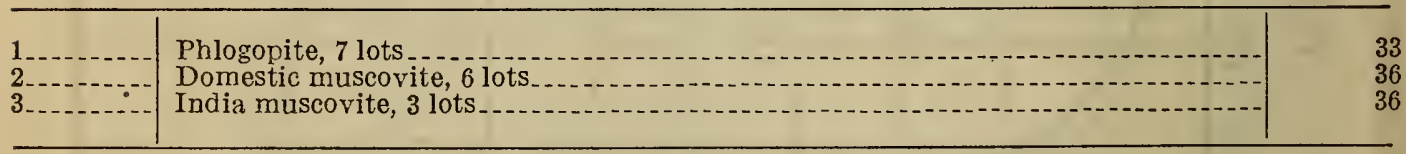

The mounted exhibit has been photographed and is shown in Figure 8. This photograph shows to some extent the changes in the surface appearance of the samples which took place on heating. An estimate of the amount of swelling which took place can be made from the length of the shadows cast by the specimens. For example, the long shadow cast by specimen L, biotite, South Dakota, at $600^{\circ} \mathrm{C}$., indicates that this sample has swelled considerably, while sample $K$, muscovite, Brazil, has been relatively unaffected by this temperature. It seems hardly necessary to emphasize the essentially qualitative nature of these particular observations. 


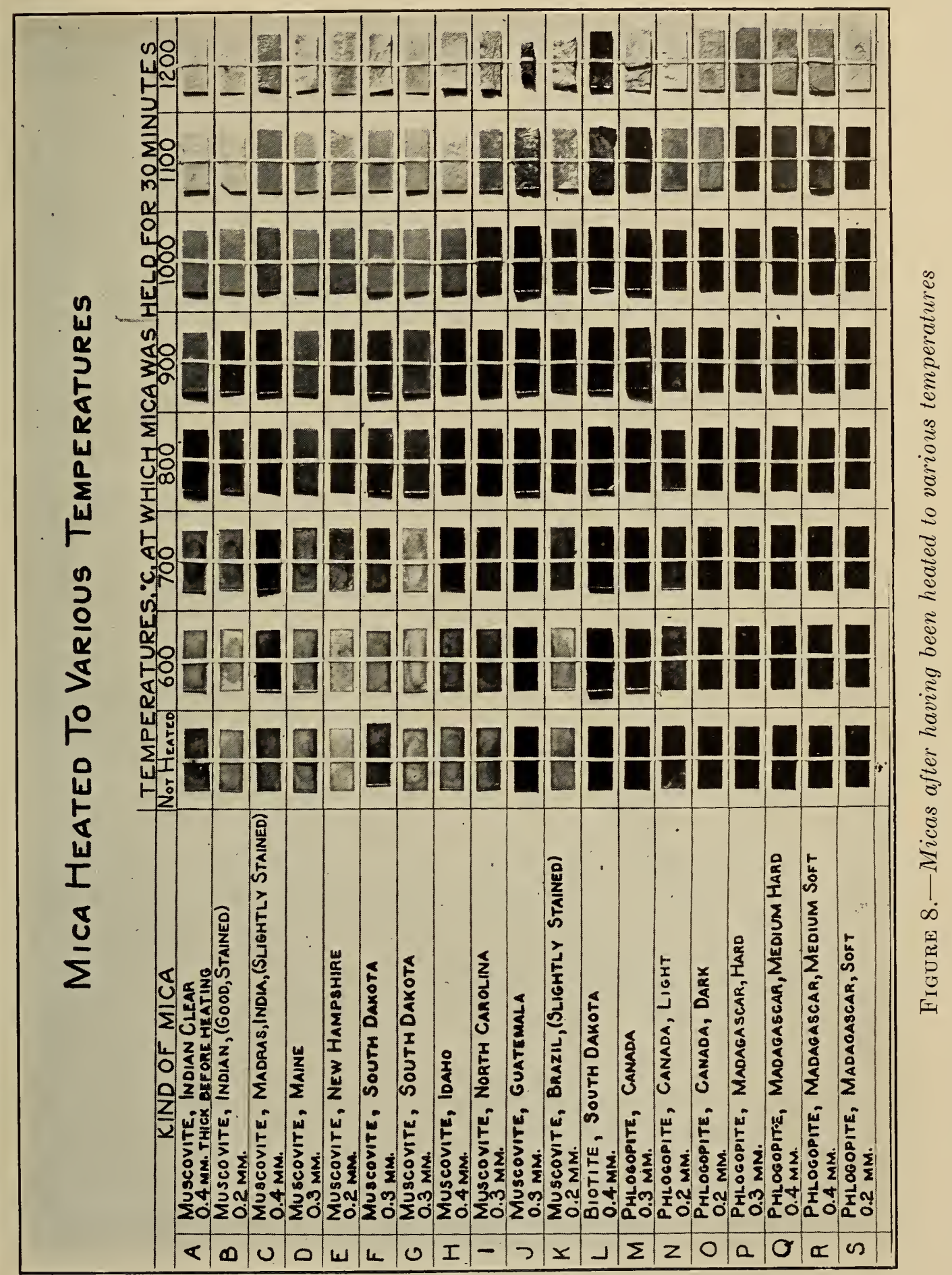




\section{DISCUSSION AND CONCLUSIONS}

From the data of Table 1 it is apparent that stained muscovite micas and phlogopite show power factors entirely too high to permit their use in applications calling for materials having low power loss. For perfectly clear muscovite mica one may predict, from these data, a power factor of 0.02 per cent with deviations from this value of \pm 0.01 per cent on the average. The average dielectric constant of these micas is found to be 7.2 with a deviation from this value of \pm 0.3 on the average.

These figures are shown (see Table 1) to be in good agreement with those reported by other observers.

From the curves of Figure 5 it is apparent that the differences between the breakdown voltages of clear ruby mica, ruby mica stained with air bubbles, and ruby mica slightly stained with metallic oxides, does not exceed that which might be expected from the normal scattering of the individual observations. (See columns $A$ and $B$ of Table 2.) The dielectric strength of mica is thus less sensitive to the presence of inclusions than is the power factor which, as is shown by the preceding section, is seriously affected by the slightest trace of air bubbles or metallic oxides. The curves for the domestic ruby micas, heavily stained with metallic oxides, show a small but definite decrease of dielectric strength due to the stains, with a correspondingly increased average scattering of the individual points, see columns $A$ and $\mathrm{B}$, Table 2. This increased scattering is particularly noticeable at the smaller thicknesses. The decrease in dielectric strength is not, however, as large as would have been expected from the appearance of the samples, which were so heavily stained as to be practically opaque.in 10-mil thicknesses.

To emphasize this last point attention should be called to the curve in Figure 5 giving the breakdown voltage of clear ruby mica from India. This curve indicates that the foreign clear ruby specimens have a dielectric strength considerably less than the foreign slightly stained specimens, lower even than the heavily. stained specimens in thicknesses less than 5 mils. No explanation is offered for this apparent anomaly except to point out that the curve for the clear India ruby mica is the average of a relatively small number of lots of mica. This curve should, therefore, perhaps be considered as being more characteristic of the individual lots used than of the corresponding class of mica in general.

Low as these values for clear India mica seem in comparison with the data on other micas, they are nevertheless in excellent agreement with values reported by Rayner. ${ }^{12}$ Rayner used as electrodes 2 -inch steel spheres immersed in oil to prevent corona and flash over. His experimental conditions were, therefore, almost identical with those of the present investigation. Although the origin of his mica samples is not specifically given, it is very probable that they came from India.

The presence of numerous thin layers of conducting material in the badly stained micas will tend to seriously distort the electric field within the crystal. This is probably the explanation both for the increased scattering of the results obtained on these badly stained samples, and for the preliminary sparking which took place at the electrodes. 
It is not possible on the basis of the data recorded in Table 4 to make any distinction between micas of like quality obtained from different geographical locations. We see from these data that not only are the average values of breakdown voltage practically indistinguishable, but that the scattering of results obtained on micas taken from widely separated localities is no greater than the scattering of results obtained on micas taken from the same State, or even from the same county.

Other observers working on the dielectric strength of thin films have arrived at the conclusion that the dielectric strength, expressed as volts per mil, should vary inversely as the thickness of the specimen. Joffé ${ }^{13}$ arrived at this conclusion from theoretical considerations and confirmed it by experiments on thin glass films. Moon and Norcross ${ }^{14}$ have reached the same conclusion as a result of experiments on thin mica films. All of these observations were taken on thicknesses below 2 mils. In Figure 7 are shown the curves obtained by fitting, by least squares, the two laws

and

$$
K V / \mathrm{mil}=\frac{A}{t}+B
$$

$$
K V / \mathrm{mil}=\frac{A}{\sqrt{t}}+B
$$

to the same set of data. Here $t$ is the thickness in mils, $A$ and $B$ are constants. It is seen that below about 3 mils the two laws are practically identical and, with such data as is here presented, it would be impossible to distinguish between them. For thicker specimens, however, the observed values of $K V / \mathrm{mil}$ fall off more rapidly than $\frac{1}{t}$ and over the range from $0.1 \mathrm{mil}$ to 17 mils (see figs. 6 and 7 ) the data seems to be most adequately represented by the equation

$$
K V / \mathrm{mil}=\frac{A}{\sqrt{t}}+B
$$

From an observation of the mounted exhibit (see fig. 8) it is apparent that, with one or two exceptions, all of the samples remained practically unchanged after exposure to $600^{\circ} \mathrm{C}$. Above this temperature (see Table 3) the phlogopites retained their initial properties to a greater extent than the muscovites or the biotite. None of the micas investigated withstands $1,200^{\circ} \mathrm{C}$. well, and except for possible exceptional uses, they may be said to have undergone such great changes as to be rendered unsuitable for use.

Finally it was not found possible on the basis of the data presented in Tables 1,2, and 3 to make any essential distinction between micas of like commercial grades based solely on the geographical origin of the samples.

Washington, May 22, 1931.

13 A. Joffé, The Mechanism of Dielectric Breakdown, J. Math. and Physics, M. I. T., 6, p. 133, 1926. 14 See footnote 6, p. 407. 